\title{
Successful Use of Nivolumab in a Patient with Head and Neck Cancer After Allogeneic Bone Marrow Transplantation
}

This article was published in the following Dove Press journal: OncoTargets and Therapy

\section{Xiaopei Dong \\ Ning Lu \\ Zhongsheng Tong \\ Yehui Shi}

Department of Breast Oncology, Tianjin Medical University Cancer Institute and Hospital, National Clinical Research Center of Cancer, Key Laboratory of Cancer Prevention and Therapy, Key Laboratory of Breast Cancer Prevention and Therapy, Tianjin Medical University, Ministry of Education, Tianjin, People's Republic of China
Correspondence: Yehui Shi;

Zhongsheng Tong

Tianjin Medical University Cancer Institute and Hospital, West Huan-Hu

Road, Ti Yuan Bei, Hexi District, Tianjin, 300060, People's Republic of China

Tel +86 I862222II83; +86 I862222II8I

Email shiyehui@tjmuch.com;

tongzhongsheng@tjmuch.com

\begin{abstract}
Recently, programmed cell death 1(PD-1) inhibitors have shown a significant curative effect in the treatment of most solid cancers and some hematological malignancies. The effects of PD-1 inhibitors in recurrent head and neck squamous cell carcinoma (HNSCC) have also been confirmed. However, there is a lack of reliable clinical evidence to confirm the safety and efficacy of PD-1 inhibitors in patients after allogeneic hematopoietic stem cell transplantation, especially when the patient has a second primary cancer. Generally, graftversus-host disease (GVHD) is unpredictable among these patients. Here we report the case of a patient who successfully used nivolumab without any GVHD or other immune-related adverse events for HNSCC after allogeneic bone marrow transplantation because of the Philadelphia chromosome-positive T cell acute lymphoblastic leukemia.
\end{abstract}

Keywords: programmed cell death 1 inhibitor, nivolumab, head and neck squamous cell carcinoma, allogeneic hematopoietic stem cell transplantation, graft-versus-host disease

\section{Introduction}

Head and neck squamous cell carcinoma (HNSCC) is one of the major causes of cancer-associated illness and death, with more than 600,000 newly diagnosed cases worldwide each year ${ }^{1}$ and a continuously increasing incidence rate. ${ }^{2}$ HNSCC includes cancers of the oral cavity, pharynx, and larynx. The anatomical structures of the head and neck can be damaged by the tumor itself or treatments such as surgical resection and chemoradiotherapy, which sometimes cause speech, swallowing, and breathing impairments. ${ }^{3,4}$ Patients with HNSCC have been shown to bear greater psychological distress than those with other types of cancer. ${ }^{5}$

Despite the currently available therapies, patients with advanced HNSCC still experience poor outcomes. ${ }^{6-8}$ For example $>50 \%$ of patients with locoregionally advanced HNSCC experience recurrence or metastases development within 3 years of treatment. $^{9-11}$ Treatment options for patients with the recurrent and metastatic disease following progression after a platinum-based regimen are limited, and the median overall survival of such patients is less than 7 months. ${ }^{12-15}$

The recurrence and metastasis of HNSCC are facilitated by immune evasion; ${ }^{16}$ therefore, as one of the methods to inhibit immune evasion, the use of programmed death 1 (PD-1)/programmed death ligand 1 (PD-L1) pathway inhibitors is considered effective in the treatment of recurrent HNSCC. ${ }^{17-19}$ Nivolumab, a fully human IgG4 anti-PD-1 monoclonal antibody, has shown remarkable antitumor efficacy 
and safety when administered to patients with recurrent HNSCC whose disease had progressed within 6 months of platinum-based chemotherapy; ${ }^{19}$ Furthermore, nivolumab treatment has been shown to improve the quality of life of these patients. ${ }^{20}$ However, PD-1 inhibitors can upregulate $\mathrm{T}$ cells in vivo, which may lead to the development of graft-versus-host disease (GVHD) in patients after allogeneic hematopoietic stem cell transplantation (alloHSCT) ${ }^{21-23}$ To the best of the authors' knowledge, no studies have investigated the safety and efficacy of nivolumab in patients with HNSCC after allo-HSCT. Here, we report the case of a patient who experienced excellent control of left buccal squamous cell carcinoma with nivolumab after the failure of platinum-based chemotherapy despite receiving allogeneic bone marrow transplantation.

\section{Case Presentation}

Without any family history of tumor, a 33-year-old man was diagnosed with Philadelphia chromosome-positive T cell acute lymphoblastic leukemia on March 19, 2014. $\mathrm{He}$ received one course of vincristine and prednisone therapy and four courses of vincristine, daunorubicin, cyclophosphamide, and prednisone therapy. He was in complete remission at the end of therapy. Subsequently, allogeneic bone marrow transplantation was performed; the donor was his human leukocyte antigen (HLA)haploidentical sibling (sister). He experienced chronic GVHD (c GVHD) of the oral cavity and skin 3 months after transplantation, for which he was treated with steroid hormone- and cyclosporine-based therapies. Skin rejection lasted for more than 3 years. Imatinib mesylate was administered for 2 years after transplantation, and his leukemia was well controlled.

In August 2018, the patient developed an ulcer of approximately $0.5 \times 0.5 \mathrm{~cm}$ size in the left buccal mucosa; the ulcer was slightly painful and covered with white moss. In September 2018, the patient was admitted to Peking University Stomatological Hospital, where a biopsy of the buccal mucosa was performed. The pathology results showed the presence of squamous cell carcinoma in the left cheek. Unfortunately, this patient was not a right candidate for HNSCC in terms of exposure to risk factors, such as long terms of smoking and drinking. On October 10, 2018, ${ }^{18}$ F-fluorodeoxyglucose-positron emission tomography/computed tomography (CT) showed that the mass in the left cheek was metabolically active, which is consistent with the activity of a malignant tumor. One course of an adjuvant therapy regimen (nimotuzumab
[200 mg d0] + docetaxel $[60 \mathrm{mg} \mathrm{d} 1,8]+$ nedaplatin [60 mg d2, 3]) was administered on October 26, 2018. Following this, the patient developed degree II thrombocytopenia and redness, swelling, and ulceration of the cheek, which had discharge with a peculiar smell. On November 29, 2018, a head and neck CT scan showed a left buccal malignant tumor with the destruction of the neighboring mandibular bone and lymph node enlargement in the left submaxillary region and right carotid sheath. The CT examination revealed disease progression. Following a multidisciplinary consultation in our hospital, surgery was not recommended; instead, a chemotherapybased comprehensive treatment was recommended as a better option for the patient. The patient received chemotherapy with albumin paclitaxel $(200 \mathrm{mg} \mathrm{d} 1,8)+$ bleomycin $(15,000$ units $\mathrm{d} 2,9)$ from November 30, 2018 to January 9, 2019. On another CT scan, the curative effect was evaluated as partial remission (showed in Video 1, Figure 1A); subsequently, two courses of a chemotherapy regimen comprising nivolumab $(140 \mathrm{mg} \mathrm{d} 1)+$ albumin paclitaxel (200 mg d1, d8) were administered. A CT examination showed stable disease (SD) on March 12, 2019, following which the patient was administered $120 \mathrm{mg}$ of nivolumab once every 2 weeks from March 15 to May 23, 2019. Another CT examination was performed on May 28 , 2019 (showed in Video 2, Figure 1B). During the therapy course, the related tumor markers showed an overall downward trend, the new metastases did not appear, the patient's status became better than before. Subsequently, another CT examination performed in August 02, 2019 showed the extent of the tumor was obvious reduction than before (showed in video 3, Figure 1C). And the corresponding CT report in August 02, 2019 was described as follows - Compared with the CT on 28 May, 2019, the extent of the tumor in the left cheek became obviously smaller, the tubercle in the left submandibular and the lymph nodes in the left neck also became smaller. There were no other significant changes in this image. Most importantly, the patient did not develop any form of GVHD following nivolumab administration.

\section{Discussion and Conclusion Nivolumab Treatment for Patients with HNSCC}

Reliable data on the clinical safety and efficacy of nivolumab in the treatment of recurrent or metastatic HNSCC have been obtained in a Phase III randomized clinical trial (CheckMate 


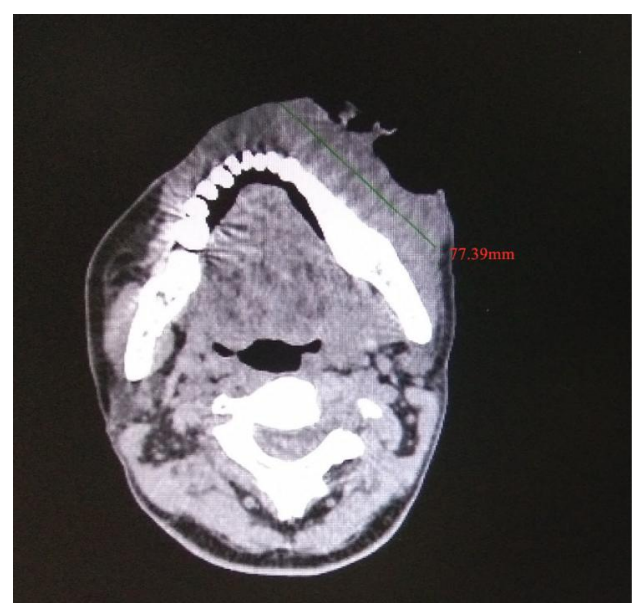

A

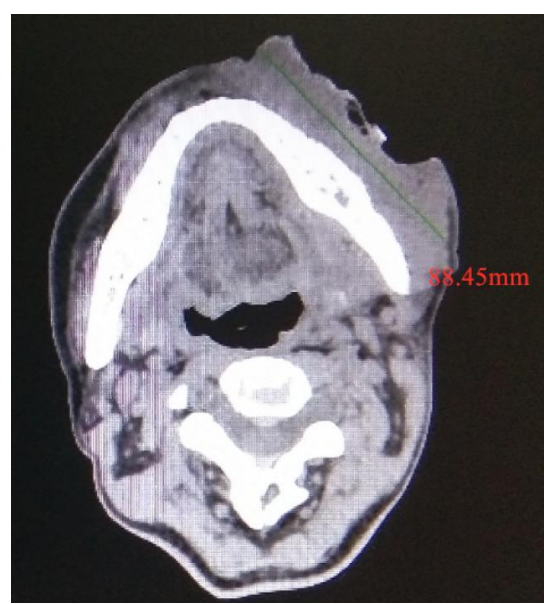

B

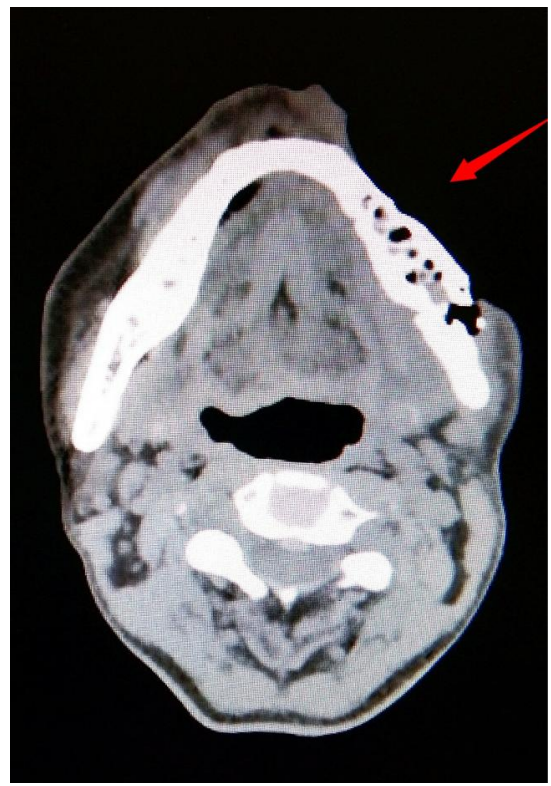

C

Figure I Head and neck CT images showing tumor before (A) and after treatment with nivolumab (B, C, respectively). Note: The arrows indicate the maximum length diameter of tumor or tumor site. Abbreviation: CT, computed tomography.

141). ${ }^{19}$ In this trial, 361 patients with recurrent HNSCC for whom disease had progressed within 6 months after platinum-based chemotherapy were enrolled between May 29, 2014, and July 31, 2015. The median follow-up duration for overall survival (OS) was 5.1 months (range, 0-16.8 months). OS was significantly greater in patients randomized to receive nivolumab than in those who received standard second-line, single-agent systemic therapy with either methotrexate, docetaxel, or cetuximab (hazard ratio, $0.70 ; 97.73 \%$ confidence interval (CI), 0.51-0.96; $\mathrm{P}=0.01$ ). The median OS was 7.5 months (95\% CI, 5.5-9.1) in the nivolumab group versus 5.1 months $(95 \% \mathrm{CI}, 4.0-6.0)$ in the standard therapy group. The one-year survival was also greater in patients who received nivolumab than in those who received standard therapy $(36.0 \%$ vs. $16.6 \%)$. Furthermore, the response rate was higher in those who received nivolumab than in those who received standard therapy (13.3\% vs 5.8\%); however, the median progressionfree survival was not significantly different between the groups ( 2.0 vs 2.3 months; $\mathrm{P}=0.32$ ). In this study, patients who were treated with nivolumab had a longer OS than those treated with standard therapy, regardless of tumor PD-L1 
expression or p16 status. Grade 3 or 4 treatment-related adverse events occurred in $13.1 \%$ of patients who received nivolumab and $35.1 \%$ of those who received standard therapy. Physical function, role functioning, and social functioning were stable in the nivolumab group, whereas they were substantially worse in the standard therapy group. ${ }^{20}$ Moreover, among Asian patients, the survival benefits were consistent with the global group. ${ }^{24}$

\section{Safety and Efficacy of Nivolumab After Allo-HSCT}

It was unclear whether nivolumab could be used in patients with recurrent HNSCC after allo-HSCT, though Khaddour et al proved the efficacy and safety of Pembrolizumab in patients who underwent allo-HSCT after relapsed and refractory Sézary Syndrome and cutaneous squamous cell carcinoma. ${ }^{25}$ However, some case reports (Table 1) and clinical trials (Table 2) have reported the efficacy and safety of nivolumab when administrated to patients with recurrent hematological malignancies (mostly Hodgkin's lymphoma) after allo-HSCT.

In Herbaux et al, nivolumab ( $3 \mathrm{mg} / \mathrm{kg}$, once every 2 weeks) was administered to 20 patients with Hodgkin's lymphoma who experienced relapse after allo-HSCT. The overall response rate was $95 \%$, the 1 -year progression-free survival rate was $58.2 \%$, and the 1 -year OS rate was $78.8 \%{ }^{26}$ Compared with other treatment options, nivolumab was more effective in these patients. ${ }^{27-30}$ Haverkos et al reported results after a median follow-up duration was 428 days (range, 133-833 days). After treatment with PD-1 inhibitors [nivolumab $3 \mathrm{mg} / \mathrm{kg}$, once every 2 weeks $(\mathrm{n}=28)$ and pembrolizumab $(\mathrm{n}=3)]$, the overall response rate of 31 patients with relapsed lymphoma after alloHSCT was $77 \%$, the median progression-free survival was 591 days (range,400-644 days), and 68\% of the patients survived to the end of the study. ${ }^{23}$ These two studies showed that nivolumab is effective when administered to patients with recurrent blood cancers after alloHSCT, which is consistent with the results of several other case reports $^{31-34}$ and case series. ${ }^{35,36}$ The PD-1/PD-L1 pathway plays a key role in the regulation of the balance among $\mathrm{T}$ cell activation, $\mathrm{T}$-cell tolerance, and immunemediated tissue damage. This pathway protects healthy cells from excessive inflammatory or autoimmune responses. ${ }^{37,38}$ Some studies have shown that the activation of the PD-1/PD-L1 pathway can reduce acute and

Table I Case Reports of Nivolumab Use After Allo-HSCT

\begin{tabular}{|c|c|c|c|c|c|c|c|}
\hline Study & $\begin{array}{l}\text { Dose } \\
(\mathrm{mg} / \mathrm{kg})\end{array}$ & $\begin{array}{l}\text { Primary } \\
\text { Disease (n) }\end{array}$ & $\begin{array}{l}\text { Prior GVHD } \\
\text { (Grade) }\end{array}$ & Interval & Response & $\begin{array}{l}\text { GVHD } \\
\text { (Grade) }\end{array}$ & Other Outcomes (n) \\
\hline $\begin{array}{l}\text { Angenendt } \\
\text { et al, }{ }^{31} 2016\end{array}$ & 3 & $\mathrm{HL}(\mathrm{I})$ & None & 1.5 years & $\mathrm{CR}$ & None & Mild fever \\
\hline $\begin{array}{l}\text { Yared et al, } \\
2016\end{array}$ & $0.5-3$ & $\mathrm{HL}(\mathrm{I})$ & None & $\begin{array}{l}7 \\
\text { months }\end{array}$ & PR & None & Pneumonitis, hepatitis \\
\hline $\begin{array}{l}\text { Onizuka et al, }{ }^{33} \\
2017\end{array}$ & $0.5-2$ & $\mathrm{HL}(\mathrm{I})$ & aGVHD (3) & I.I years & PR & cGVHD & None \\
\hline $\begin{array}{l}\text { Shad et al, }{ }^{34} \\
2016\end{array}$ & 3 & $\mathrm{HL}(3)$ & None & 1.2 years & $C R$ & None & None \\
\hline $\begin{array}{l}\text { Albring et al, }{ }^{43} \\
2016\end{array}$ & $* *$ & AML (3) & None/none/none & $\begin{array}{l}8 \mathrm{~m} / \mathrm{NA} / \\
5 \mathrm{~m}\end{array}$ & CR/SD/PD & $\begin{array}{l}\text { aGVHD (2)/ } \\
\text { none/none }\end{array}$ & $\begin{array}{l}\text { Pancytopenia/myalgias/ } \\
\text { pancytopenic }\end{array}$ \\
\hline $\begin{array}{l}\text { Godfrey et al, }{ }^{35} \\
2017\end{array}$ & 3 & $\mathrm{HL}(3)$ & $\begin{array}{l}\text { None/cGVHD/ } \\
\text { cGVHD }\end{array}$ & đNA & $\mathrm{PR} / \mathrm{PR} / \mathrm{PR}$ & None & $\begin{array}{l}\text { Keratoconjunctivitis (2)/ } \\
\text { rash (I) }\end{array}$ \\
\hline $\begin{array}{l}\text { Cheikh et al, }{ }^{36} \\
2017\end{array}$ & 3 & $\mathrm{HL}(2)$ & None (2) & NA & $\mathrm{CR} / \mathrm{CR}$ & $\begin{array}{l}\text { GVHD (3)/ } \\
\text { GVHD (3) }\end{array}$ & $\begin{array}{l}\text { Death due to fungal } \\
\text { infection (I) }\end{array}$ \\
\hline $\begin{array}{l}\text { Covut et al, } \\
2017\end{array}$ & NA & $\mathrm{HL}(2)$ & None/GVHD (2) & $\begin{array}{l}12 \mathrm{~m} / \\
\mathrm{NA}\end{array}$ & CR/PD & None/none & $\begin{array}{l}\text { Death due to hepatic } \\
\text { failure (I) }\end{array}$ \\
\hline
\end{tabular}

Notes: **One patient received a single dose of $100 \mathrm{mg}$, one received a low-dose regimen of $0.3-\mathrm{I} \mathrm{mg}$ nivolumab per $\mathrm{kg}$ body weight weekly for a total of five infusions, and one received 2 injections (100 mg each). IDisease relapse occurred at an average of 1008 days from allo-HSCT (I8I, 389, and 2456 days).

Abbreviations: HL, Hodgkin's lymphoma; AML, acute myelocytic leukemia; aGVHD, acute graft-versus-host disease; cGVHD, chronic graft-versus-host disease; interval, the interval between allo-HSCT and nivolumab administration; CR, complete remission; PR, partial remission; SD, disease stabilization; NA, not available. 
Table 2 Studies on Nivolumab Use After Allo-HSCT

\begin{tabular}{|c|c|c|c|c|c|c|c|c|c|}
\hline Study & $\begin{array}{l}\text { N, nl, } \\
\text { n2 }\end{array}$ & $\begin{array}{l}\text { Dose } \\
\text { (mg/kg) }\end{array}$ & $\begin{array}{l}\text { Interval } \\
\text { (m) }\end{array}$ & $\begin{array}{l}\text { Median Follow- } \\
\text { Up (m) }\end{array}$ & $\begin{array}{l}\text { ORR } \\
\%\end{array}$ & $\begin{array}{l}\text { Response } \\
\text { (\%) }\end{array}$ & $\begin{array}{l}\text { aGVHD, } \\
\%\end{array}$ & $\begin{array}{l}\text { cGVHD, } \\
\%\end{array}$ & $\begin{array}{l}\text { Prior } \\
\text { GVHD, \%\& }\end{array}$ \\
\hline $\begin{array}{l}\text { Herbaux et al, }{ }^{45} \\
2015\end{array}$ & $12,12,8$ & 3 & 11 & 2 & 58 & $\begin{array}{l}\text { CR (25) PR } \\
(33)\end{array}$ & 17 & 0 & 100 \\
\hline $\begin{array}{l}\text { Schoch et al, }{ }^{46} \\
2016\end{array}$ & $9,6, N A$ & NA & 14.4 & 24 & NA & NA & 0 & 0 & NA \\
\hline $\begin{array}{l}\text { Herbaux et al, }{ }^{26} \\
2017\end{array}$ & $20,20,19$ & 3 & $8.5 / 28.5^{*}$ & 12.3 & 95 & $\begin{array}{l}C R(42) P R \\
(52)\end{array}$ & 30 & 0 & 100 \\
\hline $\begin{array}{l}\text { Haverkos et al, } \\
2017\end{array}$ & $\begin{array}{l}31,28 \\
30\end{array}$ & 3 & $\geq 24$ & 14 & 77 & $\begin{array}{l}C R(50) P R \\
(27)\end{array}$ & 19 & $32 \oint$ & 39 \\
\hline $\begin{array}{l}\text { Davids et al, }{ }^{47} \\
2017\end{array}$ & $8,8,8$ & $1,0.5 \S$ & NA & 8 & 17 & PR (17) & 0 & 13 & NA \\
\hline
\end{tabular}

Notes: \&Patients who had nivolumab-related GVHD. *Patients who had nivolumab-induced GVHD vs. no nivolumab-induced GVHD (median, 8.5 months vs median, 28.5 months). $\oint$ Four patients had overlap GVHD. §Six patients received I mg/kg and two patients received $0.5 \mathrm{mg} / \mathrm{kg}$.

Abbreviations: $\mathrm{N}$, total number of patients; $\mathrm{nl}$, patients using nivolumab; $\mathrm{n} 2$, evaluable patients for the response; Interval, interval between allo-HSCT and nivolumab administration; ORR, objective response rate; CR, complete remission; PR, partial remission; allo-HSCT, allogeneic hematopoietic stem cell transplantation.

chronic GVHD, whereas its blockade can accelerate the graft-versus-host response and increase the associated mortality. ${ }^{21,22,39}$ It is unclear whether the PD-1 inhibitor nivolumab increases the risk of GVHD and the associated mortality in patients after allo-HSCT. ${ }^{23,26}$ Some clinical studies and case reports have shown that nivolumab treatment-related GVHD and consequent death in patients after allo-HSCT might be affected by the following factors. First, GVHD after anti-PD-1 treatment has been observed most frequently in matched sibling donor transplants; for which Haverkos et al reported an incidence of $75 \% .{ }^{23}$ In a Phase I pilot study, without GVHD or G3/G4 immune toxicity after receiving multiple doses of nivolumab was only among one patient whose donor source was Haploidentical+cord blood Fludarabine. ${ }^{40}$ Second, a history of GVHD, especially for the acute GVHD, may lead to an increased risk of nivolumab treatment-related GVHD after allo-HSCT. In a French cohort, all patients who presented with acute GVHD after nivolumab treatment had a prior history of acute GVHD, among which three patients presented with steroid-refractory nivolumabinduced GVHD, and GVHD was not observed among patients without a history of GVHD. ${ }^{26}$ This phenomenon was also observed in Steinerová's medical report. ${ }^{41}$ In the study by Haverkos et al, $63 \%$ of patients with a history of GVHD prior to anti-PD-1 treatment developed treatmentemergent GVHD after receiving anti-PD-1. ${ }^{23}$ Third, the shorter the interval between transplantation and nivolumab use, the greater the risk of GVHD. In the study by
Herbaux et al, the median intervals between transplantation and nivolumab use in cases with the presence and absence of GVHD were 8.5 months and 28.5 months, respectively. ${ }^{26}$ In another study by Wang et al, the reported four patients all experienced immune-related adverse events following nivolumab treatment and the median time from transplantation to nivolumab use was 7.8 months. ${ }^{40}$ Fourth, dose is a risk factor for nivolumab treatment-related GVHD. In a case report, chronic skin GVHD was observed when the dose of nivolumab was adjusted from $0.5 \mathrm{mg} / \mathrm{kg}$ to $2 \mathrm{mg} / \mathrm{kg} .{ }^{33}$ Other factors, such as immunosuppressive therapy at the time of nivolumab administration, may also influence nivolumab treatmentrelated GVHD. Recently, a comprehensive literature review was launched by Awais et al to assess the safety and efficacy of the use of checkpoint inhibitors (ipilimumab, nivolumab and pembrolizumab) in blood cancers before and after allo-HSCT. Collective data showed that checkpoint inhibitors use after allo-HSCT for posttransplant relapse had higher efficacy but the risk of GVHD was significant. Moreover, the investigation indicated that higher drug doses, shorter intervals between checkpoint inhibitors exposure and allo-HSCT and prior history of GVHD had a positive correlation with the risk of GVHD. ${ }^{42}$

\section{Nivolumab in Our Case Report}

In the present case, HNSCC was effectively controlled without any nivolumab treatment-related acute or chronic 
GVHD after nivolumab administration, while the weight loss being the only adverse event. After comprehensive analysis, we found that many factors may impede the development of nivolumab treatment-related GVHD in our patient. On one hand, the appropriate donor, no use of checkpoint inhibitors prior to allo-HSCT, the long interval between nivolumab administration and allo-HSCT (36 months) and the standard dose use of nivolumab were the negative factors for GVHD development. On the other hand, the chronic GVHD of the oral cavity and skin before nivolumab use might lead to the development of GVHD. However, it remained unknown what role the immunosuppressant therapy played in the occurrence of GVHD, though we definitely known that immunosuppressant was administered more than 2 years after allo-HSCT and discontinued for 2 years before treatment with nivolumab in our patient. Finally, whether the two primary cancers in our case affected the efficacy and safety of nivolumab by some unknown pathways were unclear, which needed further exploration.

Nivolumab has been shown to be effective in patients with HNSCC for whom platinum-based therapy has failed. However, little is known about the efficacy and safety of nivolumab in patients with HNSCC who have undergone allo-HSCT. Our case report shows that nivolumab could be used effectively and safely in such patients, however, more clinical trials are required to confirm these results.

\section{Informed Consent}

This study was approved by the Medical Ethics Committee of Tianjin Medical University Cancer Institute and Hospital. The authors state that they have obtained verbal and written informed consent from the patient for the inclusion of their medical and treatment history within this case report.

\section{Funding}

This work was supported by the Tianjin Science and Technology Commission (18ZXXYSY00070), Key Task Project of Tianjin Health and Family Planning Commission (16KG128), Anticancer Key Technologies R\&D Program of Tianjin (12ZCDZSY16200), and Natural Science Foundation of Tianjin (18JCYBJC91600).

\section{Disclosure}

The authors declare no potential conflicts of interest with respect to the research, authorship, and/or publication of this article.

\section{References}

1. Ferlay J, Soerjomataram I, Dikshit R, et al. Cancer incidence and mortality worldwide: sources, methods and major patterns in GLOBOCAN 2012. Int J Cancer. 2015;136(5):E359-E386. doi:10.1002/ijc.29210

2. Jakobsen KK, Gronhoj C, Jensen DH, et al. Increasing incidence and survival of head and neck cancers in Denmark: a nation-wide study from 1980 to 2014. Acta Oncol. 2018;57:1143-1151. doi:10.1080/ 0284186X.2018.1438657

3. Sobecki-Ryniak D, Krouse HJ. Head and neck cancer: historical evolution of treatment and patient self-care requirements. Clin J Oncol Nurs. 2013;17(6):659-663. doi:10.1188/13.CJON.659-663

4. Licitra L, Mesia R, Keilholz U. Individualised quality of life as a measure to guide treatment choices in squamous cell carcinoma of the head and neck. Oral Oncol. 2016;52:18-23. doi:10.1016/j. oraloncology.2015.10.020

5. Singer S, Krauss O, Keszte J, et al. Predictors of emotional distress in patients with head and neck cancer. Head Neck. 2012;34(2):180-187. doi: $10.1002 /$ hed. 21702

6. Licitra L, Felip E. Squamous cell carcinoma of the head and neck: ESMO clinical recommendations for diagnosis, treatment and follow-up. Ann Oncol. 2009;20(Suppl 4):121-122. doi:10.1093/annonc/mdp149

7. Adelstein D, Gillison ML, Pfister DG, et al. NCCN guidelines insights: head and neck cancers, version 2.2017. J Natl Compr Canc Netw. 2017;15(6):761-770. doi:10.6004/jnccn.2017.0101

8. Warnakulasuriya S. Global epidemiology of oral and oropharyngeal cancer. Oral Oncol. 2009;45(4-5):309-316. doi:10.1016/j. oraloncology.2008.06.002

9. Bernier J, Domenge C, Ozsahin M, et al. Postoperative irradiation with or without concomitant chemotherapy for locally advanced head and neck cancer. $N$ Engl J Med. 2004;350(19):1945-1952. doi:10.1056/NEJMoa032641

10. Blanchard P, Baujat B, Holostenco V, et al. Meta-analysis of chemotherapy in head and neck cancer (MACH-NC): a comprehensive analysis by tumour site. Radiother Oncol. 2011;100(1):33-40. doi:10.1016/j.radonc.2011.05.036

11. Tanvetyanon T, Padhya T, McCaffrey J, et al. Postoperative concurrent chemotherapy and radiotherapy for high-risk cutaneous squamous cell carcinoma of the head and neck. Head Neck. 2015;37 (6):840-845. doi:10.1002/hed.23684

12. Guardiola E, Peyrade F, Chaigneau L, et al. Results of a randomised Phase II study comparing docetaxel with methotrexate in patients with recurrent head and neck cancer. Eur J Cancer. 2004;40 (14):2071-2076. doi:10.1016/j.ejca.2004.05.019

13. Vermorken JB, Herbst RS, Leon X, Amellal N, Baselga J. Overview of the efficacy of cetuximab in recurrent and/or metastatic squamous cell carcinoma of the head and neck in patients who previously failed platinum-based therapies. Cancer. 2008;112(12):2710-2719. doi: $10.1002 /$ cncr. 23442

14. Argiris A, Ghebremichael M, Gilbert J, et al. Phase III randomized, placebo-controlled trial of docetaxel with or without gefitinib in recurrent or metastatic head and neck cancer: an eastern cooperative oncology group trial. J Clin Oncol. 2013;31(11):1405-1414. doi:10.1200/JCO.2012.45.4272

15. Saloura V, Cohen EEW, Licitra L, et al. An open-label single-arm, phase II trial of zalutumumab, a human monoclonal anti-EGFR antibody, in patients with platinum-refractory squamous cell carcinoma of the head and neck. Cancer Chemother Pharmacol. 2014;73 (6):1227-1239. doi:10.1007/s00280-014-2459-z

16. Ferris RL. Immunology and Immunotherapy of head and neck cancer. J Clin Oncol. 2015;33(29):3293-3304. doi:10.1200/JCO.2015.61.1509

17. Chow LQM, Haddad R, Gupta S, et al. Antitumor activity of pembrolizumab in biomarker-unselected patients with recurrent and/or metastatic head and neck squamous cell carcinoma: results from the phase Ib KEYNOTE-012 expansion cohort. J Clin Oncol. 2016;34 (32):3838-3845. doi:10.1200/JCO.2016.68.1478 
18. Seiwert TY, Burtness B, Mehra R, et al. Safety and clinical activity of pembrolizumab for treatment of recurrent or metastatic squamous cell carcinoma of the head and neck (KEYNOTE-012): an open-label, multicentre, phase 1b trial. Lancet Oncol. 2016;17(7):956-965. doi:10.1016/S1470-2045(16)30066-3

19. Ferris RL, Blumenschein G Jr, Fayette J, et al. Nivolumab for recurrent squamous-cell carcinoma of the head and neck. $N$ Engl $J$ Med. 2016;375(19):1856-1867. doi:10.1056/NEJMoa1602252

20. Harrington KJ, Ferris RL, Blumenschein G Jr, et al. Nivolumab versus standard, single-agent therapy of investigator's choice in recurrent or metastatic squamous cell carcinoma of the head and neck (CheckMate 141): health-related quality-of-life results from a randomised, Phase 3 trial. Lancet Oncol. 2017;18:1104-1115. doi:10.1016/S1470-2045(17)30421-7

21. Blazar BR, Carreno BM, Panoskaltsis-Mortari A, et al. Blockade of programmed death-1 engagement accelerates graft-versus-host disease lethality by an IFN-gamma-dependent mechanism. $J$ Immunol. 2003;171:1272-1277. doi:10.4049/jimmunol.171.3.1272

22. Saha A, Aoyama K, Taylor PA, et al. Host programmed death ligand 1 is dominant over programmed death ligand 2 expression in regulating graft-versus-host disease lethality. Blood. 2013;122:3062-3073. doi:10.1182/blood-2013-05-500801

23. Haverkos BM, Abbott D, Hamadani M, et al. PD-1 blockade for relapsed lymphoma post-allogeneic hematopoietic cell transplant: high response rate but frequent GVHD. Blood. 2017;130:221-228. doi:10.1182/blood-2017-01-761346

24. Kiyota N, Hasegawa Y, Takahashi S, et al. A randomized, open-label, Phase III clinical trial of nivolumab vs. therapy of investigator's choice in recurrent squamous cell carcinoma of the head and neck: a subanalysis of Asian patients versus the global population in checkmate 141. Oral Oncol. 2017;73:138-146. doi:10.1016/j. oraloncology.2017.07.023

25. Khaddour K, Musiek A, Cornelius LA, et al. Rapid and sustained response to immune checkpoint inhibition in cutaneous squamous cell carcinoma after allogenic hematopoietic cell transplant for sézary syndrome. J Immunol Cancer. 2019;7:338. doi:10.1186/ s40425-019-0801-z

26. Herbaux C, Gauthier J, Brice P, et al. Efficacy and tolerability of nivolumab after allogeneic transplantation for relapsed hodgkin lymphoma. Blood. 2017;129:2471-2478. doi:10.1182/blood-2016-11-749556

27. Peggs KS, Kayani I, Edwards N, et al. Donor lymphocyte infusions modulate relapse risk in mixed chimeras and induce durable salvage in relapsed patients after T-cell-depleted allogeneic transplantation for hodgkin's lymphoma. J Clin Oncol. 2011;29:971-978. doi:10.1200/JCO.2010.32.1711

28. Anastasia A, Carlo-Stella C, Corradini P, et al. Bendamustine for Hodgkin lymphoma patients failing autologous or autologous and allogeneic stem cell transplantation: a retrospective study of the fondazione Italiana linfomi. $\mathrm{Br} J$ Haematol. 2014;166:140-142. doi:10.1111/bjh.12821

29. Carlo-Stella C, Ricci F, Dalto S, et al. Brentuximab vedotin in patients with hodgkin lymphoma and a failed allogeneic stem cell transplantation: results from a named patient program at four Italian centers. Oncologist. 2015;20:323-328. doi:10.1634/theoncologist.2014-0420

30. Tsirigotis P, Danylesko I, Gkirkas K, et al. Brentuximab vedotin in combination with or without donor lymphocyte infusion for patients with hodgkin lymphoma after allogeneic stem cell transplantation. Bone Marrow Transplant. 2016;51:1313-1317. doi:10.1038/bmt.2016.129

31. Angenendt L, Schliemann C, Lutz M, et al. Nivolumab in a patient with refractory Hodgkin's lymphoma after allogeneic stem cell transplantation. Bone Marrow Transplant. 2016;51:443-445. doi:10.1038/ bmt.2015.266
32. Yared JA, Hardy N, Singh Z, et al. Major clinical response to nivolumab in relapsed/refractory hodgkin lymphoma after allogeneic stem cell transplantation. Bone Marrow Transplant. 2016;51:850-852. doi:10.1038/bmt.2015.346

33. Onizuka M, Kojima M, Matsui K, et al. Successful treatment with low-dose nivolumab in refractory hodgkin lymphoma after allogeneic stem cell transplantation. Int $J$ Hematol. 2017;106:141-145. doi:10.1007/s12185-017-2181-9

34. Shad AT, Huo JS, Darcy C, et al. Tolerance and effectiveness of nivolumab after pediatric T-cell replete, haploidentical, bone marrow transplantation: a case report. Pediatr Blood Cancer. 2017;64. doi:10.1002/pbc.26257

35. Godfrey J, Bishop MR, Syed S, Hyjek E, Kline J. PD-1 blockade induces remissions in relapsed classical hodgkin lymphoma following allogeneic hematopoietic stem cell transplantation. J Immunol Cancer. 2017;5:11. doi:10.1186/s40425-017-0211-z

36. El Cheikh J, Massoud R, Abudalle I, et al. Nivolumab salvage therapy before or after allogeneic stem cell transplantation in hodgkin lymphoma. Bone Marrow Transplant. 2017;52:1074-1077. doi:10.1038/bmt.2017.69

37. Keir ME, Butte MJ, Freeman GJ, Sharpe AH. PD-1 and its ligands in tolerance and immunity. Аnnu Rev Immunol. 2008;26:677-704. doi:10.1146/annurev.immunol.26.021607.090331

38. Francisco LM, Sage PT, Sharpe AH, The PD-1. pathway in tolerance and autoimmunity. Immunol Rev. 2010;236:219-242.

39. Fujiwara H, Maeda Y, Kobayashi K, et al. Programmed death-1 pathway in host tissues ameliorates Th17/Th1-mediated experimental chronic graft-versus-host disease. J Immunol. 2014;193:2565-2573. doi:10.4049/jimmunol.1400954

40. Wang AY, Kline J, Stock W, et al. Unexpected toxicities when nivolumab was given as maintenance therapy following allogeneic stem cell transplantation. Biol Blood Marrow Transplant. 2020;26:1025-1027. doi:10.1016/j.bbmt.2020.01.021

41. Steinerová K, Jindra P, Lysák D, Karas M. Development of resistant GvHD in a patient treated with nivolumab for hodgkins lymphoma relapse after allogeneic unrelated transplantation. Klin Onkol. 2019;32:66-69. doi:10.14735/amko201966

42. Ijaz A, Khan AY, Malik SU, et al. Significant risk of graft-versus-host disease with exposure to checkpoint inhibitors before and after allogeneic transplantation. Biol Blood Marrow Transplant. 2019;25:94-99. doi:10.1016/j.bbmt.2018.08.028

43. Albring JC, Inselmann S, Sauer T, et al. PD-1 checkpoint blockade in patients with relapsed AML after allogeneic stem cell transplantation. Bone marrow transplantation. 2017. doi:10.1038/bmt.2016.274

44. Covut F, Pinto R, Cooper BW, et al. Nivolumab before and after allogeneic hematopoietic cell transplantation. Bone marrow transplantation. 2017. doi:10.1038/bmt.2017.44

45. Herbaux C, Gauthier J, Brice P, et al. Nivolumab Is Effective and Reasonably Safe in Relapsed or Refractory Hodgkin's Lymphoma after Allogeneic Hematopoietic Cell Transplantation: A Study from the Lysa and SFGM-TC. Blood. 2015. doi:10.1182/blood. V126.23.3979.3979

46. Schoch LK, Borrello I, Fuchs EJ, et al. Checkpoint Inhibitor Therapy and Graft Versus Host Disease in Allogeneic Bone Marrow Transplant Recipients of Haploidentical and Matched Products with Post-Transplant Cyclophosphamide. Blood. 2016. doi:10.1182/blood. V128.22.4571.4571

47. Davids MS, Kim HT, Costello C, et al. Optimizing Checkpoint Blockade As a Treatment for Relapsed Hematologic Malignancies after Allogeneic Hematopoietic Cell Transplantation. Blood. 2017. doi:10.1182/blood.V130.Suppl_1.275.275 


\section{Publish your work in this journal}

OncoTargets and Therapy is an international, peer-reviewed, open access journal focusing on the pathological basis of all cancers, potential targets for therapy and treatment protocols employed to improve the management of cancer patients. The journal also focuses on the impact of management programs and new therapeutic

Submit your manuscript here: https://www.dovepress.com/oncotargets-and-therapy-journ agents and protocols on patient perspectives such as quality of life, adherence and satisfaction. The manuscript management system is completely online and includes a very quick and fair peer-review system, which is all easy to use. Visit http://www.dovepress.com/ testimonials.php to read real quotes from published authors. 